516 Süllmann, Über Umladung und Umlagerung von Farbstoffen

\title{
Bemerkungen zu der voranstehenden Arbeit von H. Süllmann
}

\section{Von R. Keller}

Gleichzeitig mit den von H. Süllmann im physiologisch-chemischen Institut der Universität Basel unternommenen Kataphorese-Versuchen wurden auch in unserem Laboratorium von Gicklhorn und Dejdar, ferner auf meine Anregung im pharmakologischen Institut der deutschen Universität (mit gütiger Erlaubnis von Professor Dr. E. Starkenstein) von H. Weden Nachprüfungen der älteren Versuche mit ganz frischem Serum, in einzelnen Fällen auch mit frischem Blut vorgenommen, da La u e $\mathbf{r}^{\mathbf{1}}$ ) in Bornsteins Laboratorium in Hamburg gefunden hatte, daß Methylenblau im Serum allein zur Kathode wandert. Vermutlich hat dieser Autor zu starke Konzentrationen von Methylenblau verwendet, wenn der Farbstoff allein oder fast allein an der Kathode erschienen ist, oder irgendeine andere Vorsichtsmaßregel außer acht gelassen.

Aus der Arbeit von H. Weden, die mit den Untersuchungen von Süllmann und denen von Gicklhorn und Dejdar übereinstimmen, geht hervor, daß bei den ersten Untersuchungen mit der Hochspannung ein unreines oder nicht mehr frisches Serum verwendet worden ist, denn der basische Farbstoff geht nicht, wie zuerst beobachtet, rein zur Anode, es geht nur ein stärkerer Anteil zur Anode als in reinem Wasser.

1) Pflügers Archiv, 1929. 